\title{
A ESCOLA INFANTIL E O CINEMA
}

\author{
Tanea Regina Pereira ${ }^{1}$ \\ trpcps@gmail.com
}

\section{ATUALIDADE}

A grande quantidade de conhecimento, em nossa atual realidade é devida à grande velocidade do desenvolvimento da tecnologia que vem interferindo na vida dos seres humanos por todo o nosso planeta. Hoje, mais do que nunca, se faz necessário pensar um novo jeito de se educar. Quando lemos Teixeira, e Lopes (2008), bem como outros autores percebemos claramente que o cenário onde se desenvolve o papel da educação é um cenário de globalização onde há uma imensa carga de informações transmitidas pelos meios de comunicação, sendo assim, uma variada fonte de saber é, com certeza, um cenário onde crescem as diferenças entre ricos e pobres, negros e brancos, privilegiados e injustiçados. É um cenário de constantes mudanças e assim, vamos tomando consciência de que devemos fazer uma educação voltada para a questão social.

Neste cenário de globalização e mudanças vamos percebendo que o cinema é uma forma audiovisual sofisticada, mas que, ao mesmo tempo, consegue despertar a emoção humana. Consegue transmitir alegria, tristeza, paz, raiva, esperança. Faz brotar sonhos perdidos, além de possibilitar aos sujeitos novas compreensões do mundo. Assim, na escola, o filme pode se um excelente recurso didático para o professor, muito embora, tenhamos consciência de que ele é apenas um recurso e nunca poderá substituir o professor pois, este dialoga com o aluno em tempo real. Quando o professor estabelece relações entre o tema do filme e o assunto do estudo, ampliam-se as perspectivas do debate para além das expectativas, pois o filme tem a capacidade de mexer com as emoções e com o intelecto de quem o assiste.

\section{UMA HISTÓRIA VERDADEIRA}

Acredito que por mais dificuldades que um professor possa encontrar no caminho de ensinar, ele está sempre buscando se reciclar, ou seja, ele está sempre buscando melhorar sua prática.

\footnotetext{
${ }^{1}$. Professora do CEMEI Dona Júlia dos Santos Dias - Campinas, SP.
} 
Lá por volta de 1920, surge, na história da Educação, o que chamamos de Pedagogia de Projetos. Tal proposta buscava atender melhor os interesses dos alunos. Essa Pedagogia avança nas décadas seguintes, passando por modificações e pela reflexão de grandes pedagogos nossos conhecidos. Hoje, tal pedagogia imprime um forte aspecto interdisciplinar, consolidando-se como uma metodologia que reflete sobre a escola e a vida em busca de superar as divisões presentes no currículo escolar.

Assim, penso que quando uma escola faz a opção pelo trabalho com projetos se desafia a reconstruir o conceito de escola. Quando um professor planeja suas aulas a partir dos desejos, dos interesses dos seus alunos, ele abre a possibilidade de romper com a idéia de que é obrigatório vencer um conteúdo como se houvesse uma ordem cronológica para a aprendizagem. Na Metodologia de Projetos, além do conteúdo, torna-se fundamental despertar o interesse, a curiosidade e a criatividade. $\mathrm{O}$ aluno é estimulado, desafiado a conhecer o novo. Desta forma torna-se possível colocar os conteúdos universais transitando pelo universo da escola de forma modificada, fortemente marcada pelo interesse do aluno, favorecendo que a aprendizagem aconteça com a significação necessária e a possibilidade de sínteses superadoras que facilitem o trânsito entre o mundo cotidiano e o conhecimento sistematizado sem maiores traumas.

Para Barbosa e Horn (2008, p. 31)

"Conforme o Dicionário Aurélio (1995), a palavra projeto significa atirar longe, arremessar, planejar, isto é, pensar e/ou fazer uma ação direcionada para o futuro. É um plano de trabalho, ordenado e particularizado para seguir uma idéia ou um propósito, mesmo que vagos. Um projeto é um plano com características e possibilidades de concretização. Um plano de ação com finalidades que potencializam a capacidade de avaliar o futuro a quem o propõe ou o vive; que, por antecipar-se na consciência e ter como base o passado e o presente, oferece uma conseqüente capacidade metodológica para a escolha dos meios necessários para a concreta realização do plano. Um projeto pode ser esboçado por meio de diferentes representações, como cálculos, desenhos, textos, esquemas e esboços que definam o percurso a ser utilizado para a execução de uma idéia".

Assim, para a metodologia de projetos, é importante tomar como ponto de partida temas que surjam a partir do debate desencadeado pela manifestação dos interesses de toda a sala. Algo que a maioria da turma queira ou tenha interesse em conhecer.

Foi assim que, ao perceber entusiasmo das crianças pelo cinema e tendo entrado em contato com a obra de Teixeira, Lopes e Larrosa (2006), tive certeza de que esta arte tinha o poder de abrir nossos olhos, nossa mente para um mundo sem fronteiras, no qual podemos viajar tal qual acontece em nossa imaginação quando lemos os livros. Com estas ferramentas podemos ir para o passado e para o futuro; para o Sol, para a Lua ou para o mar; posso ser branco, negro ou amarelo; posso passar de bruxa feia e fada madrinha num instante; posso ser líder, rei, presidente ou vilão. 
O cinema é mais do que entretenimento, ele abre nossos olhos, colocando-os em movimento, movimentos estes que nos remetem à infância fazendo-nos lembrar de seu dinamismo e quietude, sua indisciplina, silêncio, de sua liberdade, despojamento, força e ao mesmo tempo de sua fragilidade, o olhar fascinado cheio de desejo, interrogativo e muitas vezes distraído, assim o cinema nos ajuda a olhar e a compreender a infância mais facilmente, pois, fazer cinema não é nada fácil assim como compreender a energia da infância não é nada fácil, mas ao mesmo tempo é algo maravilhoso que se junta, que se entrelaça.

O cinema capta e constrói tempo, fantasia e nele tudo é possível e o tempo da infância assim como o tempo do cinema, é um tempo criativo criado por outra velocidade, por um outro ritmo onde tudo é permitido. Se o cinema é feito de imagens em movimento onde se incorporam palavras, sons, músicas e histórias. A infância também carrega essa característica.

O cinema, tal como os livros, faz com que os espectadores mergulhem nas personagens. Tais elementos nos remetem à fantasia infantil e, ao mesmo tempo, nos leva para o universo mítico do adolescente e do adulto. $\mathrm{O}$ cinema ainda tem como característica situar-se num universo imaginário que possibilita construir histórias em que se rompem limites do possível e do impossível desafiando o real com temáticas sentimentos e emoções que atravessam fronteiras e culturas sem precisar de passaportes ou aviões, despertando, naqueles que assistem, dor, alegrias, perdas, busca da felicidade, romance, etc.

Segundo Campbel (1990, p.23),

"esses bocados de informação, provenientes dos tempos antigos que tem a ver com os temas que sempre deram sustentação à vida humana, que construíram civilizações e informaram religiões através dos séculos, têm a ver com os profundos problemas interiores, com os profundos mistérios, com os profundos limiares da travessia, e se você não souber o que dizem os sinais ao longo do caminho, terá de produzi-los por sua conta".

\section{VIVENDO A EXPERIÊNCIA}

Educação e cinema, duas artes diferentes, mas que desde a infância me fascinaram e que na certeza fascinam milhares de pessoas.Duas artes que, para mim, se completam e que desejava ver reunidas nos tempos, nos espaços, nos projetos, enfim, no cotidiano da escola e nos processos educativos. $\mathrm{O}$ cinema participa de nossa história não apenas como tecnologia, mas criando arte e ideologia, criando ficção e realidade, produzindo memória, registros tal como acontece com a literatura, a pintura e a música. O cinema também é um meio de explorarmos os problemas do nosso tempo e de nossa existência. Assim pensando, o cinema é mais um recurso mais um instrumento, mais uma estratégia na educação e que, hoje, se faz presente na vida de todo e qualquer ser humano que habita este nosso planeta independente de servir como recurso pedagógico. 
O cinema permite a experiência estética, expressa sensibilidade e possuí múltiplas linguagens, desabrocha a criatividade se tornando importante para a educação e para os educadores. Independente de ser uma rica fonte de conhecimento e aprendizagem.

Hoje, trabalho na biblioteca da CEMEI DONA JÚLIA DOS SANTOS DIAS, uma escola materno infantil situada em Campinas, na qual os educadores optaram pela Pedagogia de Projetos. Após um período de observação e adaptação, o que é muito importante, tanto para as crianças como para os profissionais, concluí que a biblioteca também deveria caminhar conforme os interesses dos alunos, conforme propõe o Projeto Pedagógico da escola. Considero que a biblioteca deva ser um local encantado onde a fantasia dê asas à imaginação e, para isso, ela deve ser atraente, moderna, atualizada, provocante, colorida, ter sempre algo novo e interessante, capaz de despertar a curiosidade. Deve estimular a fantasia, a criatividade e deve ser sempre um prazer poder freqüentá-la. Deve despertar a responsabilidade no momento em que a criança leva e devolve o livro, atrair a curiosidade e despertar o senso crítico. Deve manusear livros. Conhecer os vários gêneros de literatura entrando em contato com autores variados. Somente na vivencia de tais gestos poderemos formar leitores, pois, tal vivência a criança levará por toda a vida.

Percebendo o grande interesse das crianças pela tecnologia e claro, pelo cinema, a biblioteca apresenta, em 2009, aos professores, um projeto para a confecção de um filme que tomaria como tema um clássico da literatura infantil: "Chapeuzinho Vermelho" onde, os personagens seriam representados pelos professores. O cenário seriam os espaços da escola, ou seja, personagens e espaços conhecidos das crianças. A experiência foi especialmente encantadora! O roteiro foi adaptado, professores se uniram, foram atores, diretores, câmeras, figurinistas e editores. as crianças ainda hoje, assistem ao filme reconhecendo os personagens, os espaços da escola, além de termos explorado questões como: medo, família, alimentação, meio ambiente, lixo, extinção de animais, realidade.

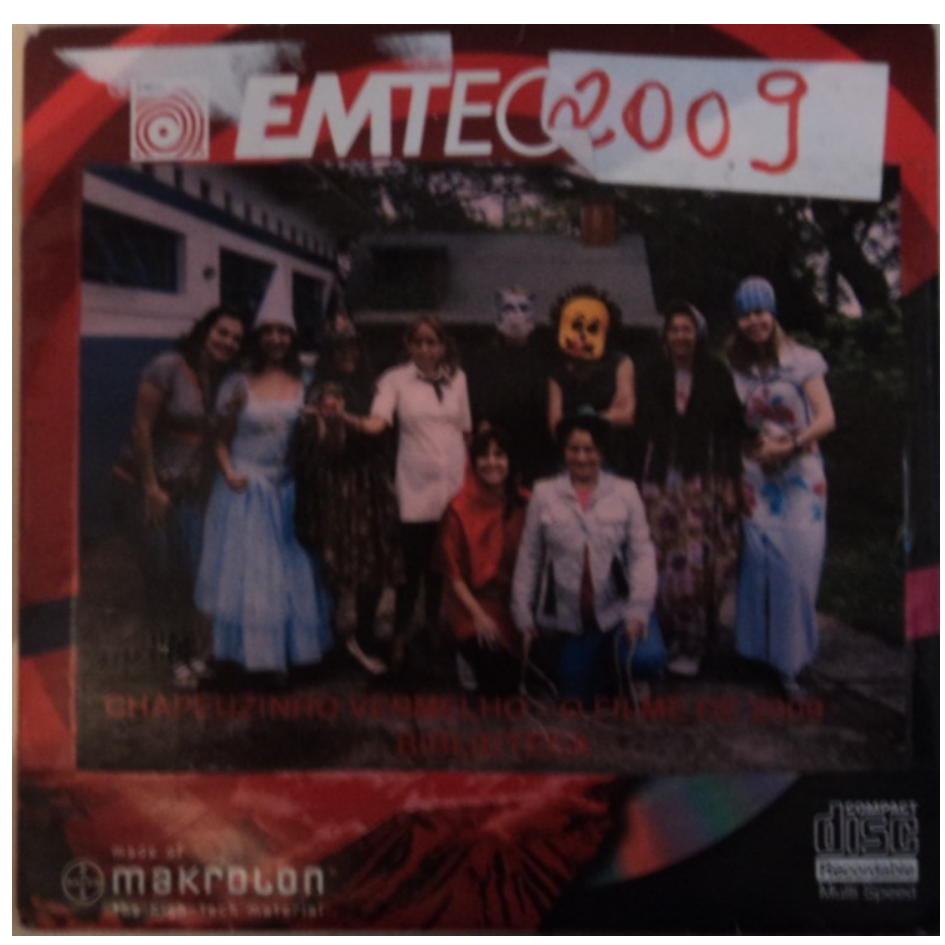
fantasia e 
Em 2010 aproveitamos o tema da diversidade para a produção de nosso segundo longa: "O Casamento de Gigi e Mustafá". Gigi era uma girafa e Mustafá um macaco. Ambos moravam na biblioteca da escola onde se conheceram e se apaixonaram. O filme foi realizado com fantoches da biblioteca e as crianças deram vida a eles com suas vozes. No dia da exibição, as crianças vieram vestidas para um casamento e, fizemos uma festa de verdade com bolo e refrigerante. Eles curtiram muito, reconhecendo o local da filmagem e cada fantoche, isso é muito legal. E, desta vez, exploramos com eles a questão do preconceito, rejeição, inclusão e exclusão. Tipos de animais e alimentação. Aos poucos foram entendendo que ninguém é igual a ninguém e que todos são iguais nos direitos e deveres. Lição esta que uma criança jamais se esquecerá. Neste mesmo processo fomos trabalhando também com o livro: "Sr. Pinguinho, O Mundo dos Pinguins" de Sérgio Vale, que, no final, foi distribuído para cada criança. Elas foram estimuladas a ler, para as pessoas de casa, aquela história que conheciam praticamente de trás para frente, e ensinar a tal lição que somos todos diferentes. Não tem ninguém igual a ninguém nem mesmo os gêmeos, mas todos devem amar e respeitar a humanidade que habita em cada um de nós, pois, um precisa do outro para ser humano.

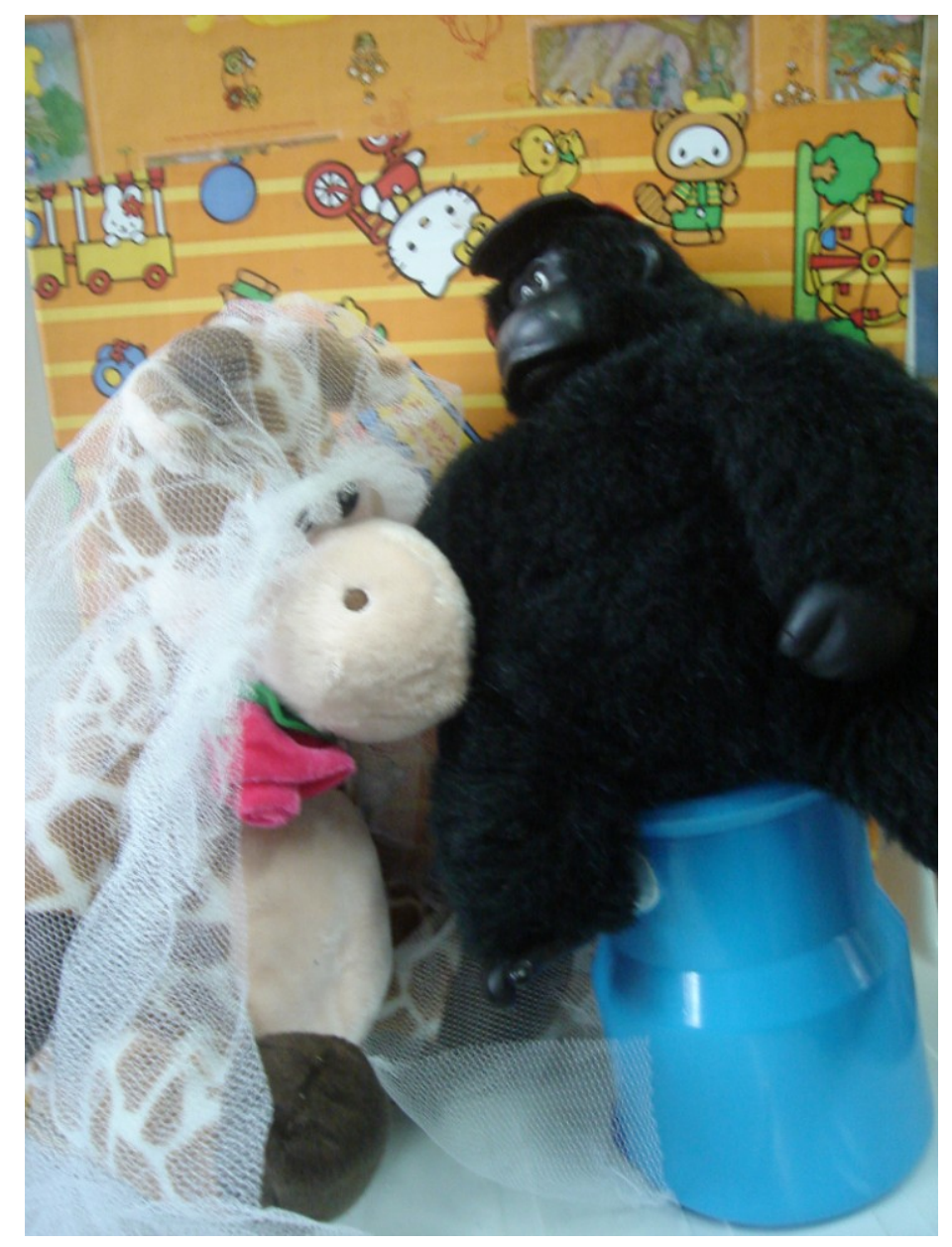


Estas experiências exitosas foram nos tornando mais ousadas e, em 2011, nos lançamos a mais um projeto, outro clássico da literatura infantil, filmamos "Branca de neve". Novamente usamos os espaços da escola. O parque se transforma na floresta, a casinha de brinquedo a casa dos anões, o espelho mágico o espelho da biblioteca, os personagens foram professores e crianças. Figurino produzido por uma educadora e, novamente foi uma experiência inesquecível! As crianças se encantaram e entraram na fantasia principalmente porque a bruxa veio assistir com eles a estréia do filme. contou que depois que deu a maçã envenenada para Branca de Neve ela ficou sozinha, ninguém mais queria ser sua amiga, ela foi isolada, todos ficaram sabendo da história. Então, a bruxa decidiu pedir desculpas. Branca de Neve a desculpou. Para que as crianças perdessem o medo dela a bruxa, então resolve visitar pessoalmente as crianças, contar que pediu desculpas levando balas feitas de maçãs. Hoje ninguém tem medo de bruxa. Muitas vezes me perguntam quando ela vai voltar, além de permitir que sua fantasia desabroche quando vão ao parque e se perdem na floresta ou encontram a casa dos sete anões, ou quando vão à biblioteca e conversam com o espelho mágico. Certo dia faltou uma professora efetiva e nossa adjunta, que havia sido a madrasta, assumiu a sala e quando a mãe perguntou a filha quem tinha ficado no lugar da professora ela não teve dúvidas e respondeu: - a madrasta. Com isso vamos explorando valores como: respeito, amizade, acolhimento, saudade, preconceito, a questão da beleza e da feiúra, e tantos outros que devem permear nossa vida para que possamos viver amanhã o sonho de uma sociedade mais justa e menos violenta.

\section{CONCLUSÃO}

assim, cheguei a conclusão de que o cinema busca trabalhar todo tempo com a emoção sincera, verdadeira com o sentimento que não é infantil, nem adulto, nem adolescente, mas totalmente sem fronteiras, pois, ele retrata questões que nos remete ao cotidiano no momento em que nos deparamos com a construção de nossa própria história nos tornando mais questionadores, críticos, mais emotivos, sensíveis e cultos.

Acredito, então, que é possível a criança ensinar ao adulto como olhar as coisas sem aquele olhar conclusivo, pois, a criança é portadora de um novo, livre, ainda inocente e capaz de surpreender. Com o cinema podemos explorar estes aspectos e produzir um olhar cheio de mistério e fantasia, assim como é o olhar da criança.

Usando o cinema como um instrumento Didático a favor da educação podemos com ele denunciar injustiças, pobreza, exclusões. Podemos levantar e discutir temas polêmicos formando cidadãos críticos e questionadores, observadores e pensantes. Podemos provocar emoções e ao mesmo tempo criar sonhos.

Concluo então, que a Câmera é tão importante para o mundo da escola quanto o lápis e a caneta o é no mundo da escola. 


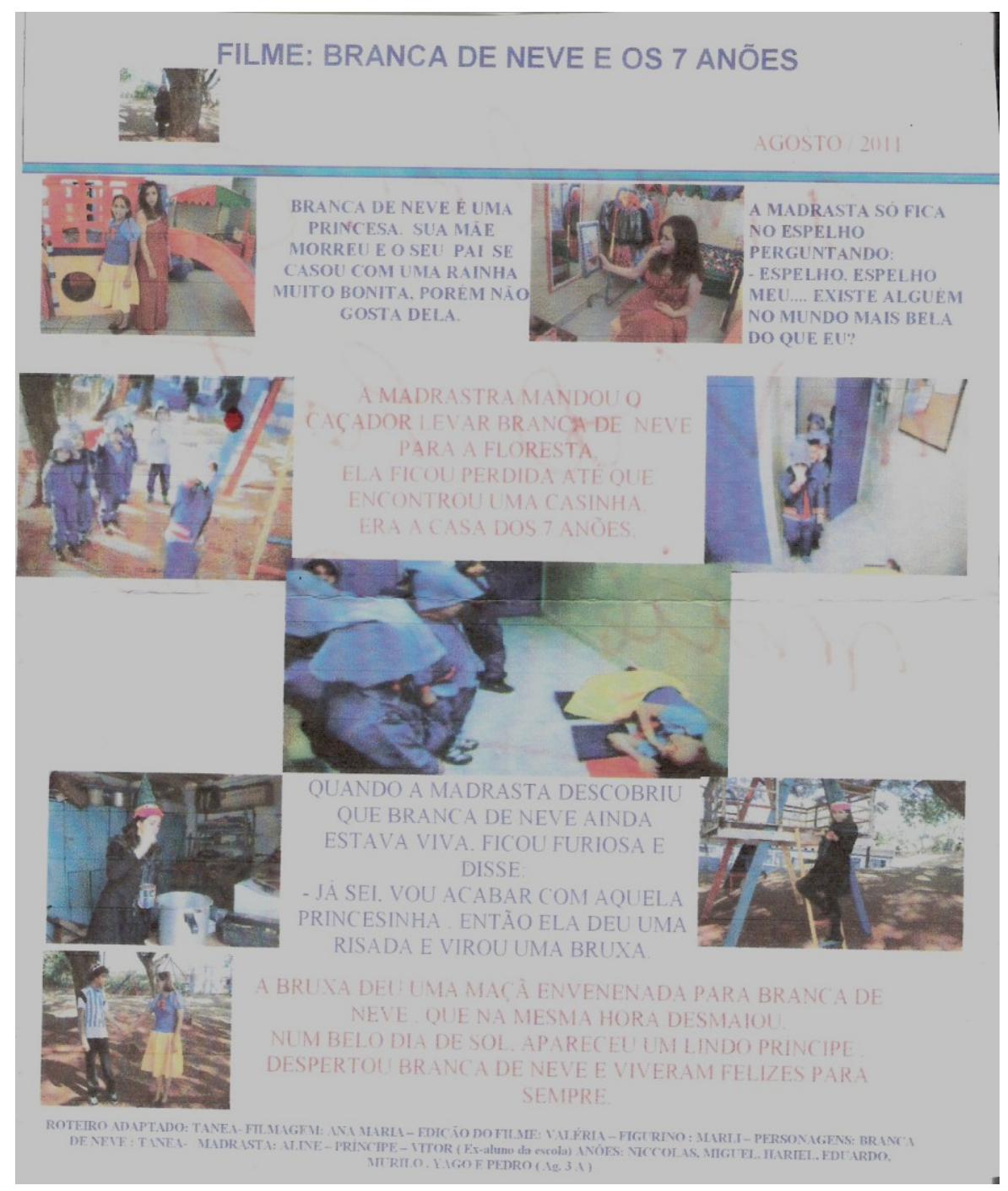

\section{BIBLIOGRAFIA:}

BARBOSA, Maria Carmem Silveira; HORN, Maria da Graça Souza. Projetos Pedagógicos na Educação Infantil. Ed. Artmed, 2008.

CAMPBEL. Joseph, O poder do mito. São Paulo: Palas Atena, 1990.

TEIXEIRA. Inês Assunção de Castro; LOPES José de Sousa Miguel. A Escola vai ao Cinema, Belo Horizonte: Autêntica, 2008.

Teixeira. Assunção de Castro; LOPES. José de Sousa Miguel, LARROSA. M Jorge, a Infância vai ao Cinema, Belo Horizonte: Autêntica, 2006. 